\title{
The association between perceived stigma and substance use disorder treatment outcomes: a review
}

This article was published in the following Dove Medical Press journal: Substance Abuse and Rehabilitation

\author{
Kathleen A Crapanzano' \\ Rebecca Hammarlund ${ }^{2}$ \\ Bilal Ahmad' \\ Natalie Hunsinger' \\ Rumneet Kullar' \\ 'Department of Psychiatry, Louisiana \\ State University Health Sciences \\ Center, Baton Rouge, LA, USA; ${ }^{2}$ Our \\ Lady of the Lake Division of Academic \\ Affairs, Baton Rouge, LA, USA
}

\begin{abstract}
Substance use disorders (SUDs) take a heavy toll on those who have them and on society more broadly. These disorders are often difficult to treat, and relapse is common. Perhaps, because of these factors, these disorders are highly stigmatized worldwide. The purpose of this study is to examine empirical work intended to determine the impact of perceived social stigma and self-stigma on the process of recovering from SUDs with the assistance of formal treatment services. Qualitative studies confirmed that stigma experiences are common among those with these disorders and that these experiences can negatively impact feelings and beliefs about treatment. One quantitative study provided good statistical support for a direct effect of stigma on outcomes, but this was contradicted by other longitudinal data. In general, quantitative articles suggested an indirect effect of stigma on treatment outcomes, via negative emotions and cognitive mechanisms such as feelings of self-efficacy. However, it was notable that there was little consistency in the literature as to definitions and measurement of the constructs of recovery, perceived social stigma, and self-stigma. Future work should focus on bringing clarity, and validated measures, to this problem in order to better determine the nature of these relationships.
\end{abstract} Keywords: self-stigma, perceived social stigma, substance use disorders, treatment outcomes

\section{Introduction}

Substance use disorders (SUDs) are defined in the Diagnostic and Statistical Manual of Mental Disorders Fifth Edition (DSM-5) as the presence of pathological behaviors associated with the use of any substance falling into one of the nine recognized classes. ${ }^{1}$ These behaviors include impaired control over use (eg, using the substance more frequently or in a higher quantity than intended), impaired social behavior (eg, failing to fulfill role responsibilities and continuing to use in spite of interpersonal problems caused by using), and risky use practices (eg, using in a physically hazardous environment or despite experiencing serious physical or psychological effects of use). ${ }^{1}$ Pharmacological effects such as tolerance and withdrawal are also criteria for diagnosis in the case of most substances. ${ }^{1}$ The severity of an SUD is graded based upon how many of these criteria the individual displays. ${ }^{1}$ Thus, not every individual diagnosed with an SUD will meet each criteria, but every individual will have experienced some negative consequences as a result of their use.

In addition to the abovementioned consequences, those who misuse substances are often subject to social consequences related to the stigmatization of substance use. Stigmatization is a societal process in which individuals within a society collectively apply stereotypes to an identifiable subgroup. ${ }^{2}$ Once a society also believes that negative
Correspondence: Kathleen A Crapanzano Department of Psychiatry, Louisiana State University Health Sciences Center, 5246 Brittany Drive, 3rd floor, Baton Rouge, LA 70808, USA

Tel + I 2257574212

Fax +I 225-757-4230

Email KcrapI@Isuhsc.edu
Substance Abuse and Rehabilitation 2019:10 I-12

Dovepress if in $\bullet$


connotations associated with stereotypes are applicable to all members of the subgroup, discrimination often results. Thus, success in all spheres of life such as employment, relationships, health, and health care can be negatively affected by stigma. Stigma against people who have SUDs is common in many societies worldwide. One WHO study found that of 18 different health conditions, drug addiction ranked as the first or second most stigmatized in 12 out of 14 countries surveyed and alcoholism ranked between second and seventh in 13 countries. $^{3}$

Although stigma against addiction may be a protective factor that deters non-users from experimenting with substance use, ${ }^{4}$ it paradoxically promotes continued use once an individual has entered the drug culture ${ }^{5}$ and may prevent access to treatment services. ${ }^{6}$ Furthermore, while societal stigma against mental illness is recognized as a problem, stigma against people with addiction is more complicated, and people with SUDs are more frequently blamed for their condition. ${ }^{7}$ When perceived societal stigma is internalized (ie, self-stigma), it can result in loss of self-respect, decreased self-esteem, and loss of self-efficacy. ${ }^{8,9}$ These feelings may harm the individual's chances of recovery from addiction.

Although there is evidence that social and self-stigma affect treatment seeking and outcomes for individuals who misuse substances, there are no systematic reviews looking at the prevalence and strength of these effects. Previous reviews in the area of stigma associated with substance misuse have focused on different aspects of the effects of stigma. In one review, Schomerus et $\mathrm{al}^{7}$ compared the evidence of stigma for alcohol dependence to that for other mental health disorders and found that people with alcohol dependence are more likely to be held responsible for their condition, to provoke more social rejection and negative emotions, and to be at particular risk for structural discrimination. A second review that focused on interventions to reduce the stigma of SUDs ${ }^{10}$ demonstrated that diverse strategies are needed to impact the different types of stigma (eg, self-stigma, social stigma, and structural stigma).

Three further reviews were more in line with the subject of this study. First, van Boekel et $\mathrm{al}^{11}$ found that negative attitudes toward people with SUDs are common among health care professionals and can contribute to poorer health care delivery. Next, Cumming et al ${ }^{12}$ found that stigma was among the most commonly cited barriers to accessing methamphetamine treatment. Finally, Moos $^{13}$ found that a significant minority of those who seek psychosocial treatment for SUDs end up worse off than before and that stigma was one of the several intervention-related variables that predicted this deterioration. However, none of these reviews directly addresses the question of whether or not self-stigma and the perception of social stigma would have an effect on an individual's ability to recover from addiction. Indeed, we could find no reviews that specifically addressed this question.

As defined by White, ${ }^{14}$ recovery from addiction is a "process and sustained status" that involves not only those with addiction but also their families and communities. All three types of persons engage "internal and external resources" to resolve addiction issues, recover from the damage these issues have caused, and "actively manage their continued vulnerability" in order to "develop a healthy, productive, and meaningful life." Given that recovery is a process rather than a specific point in time, determining when it occurs is difficult; determining the influence of various factors on recovery is even more so. The purpose of this study is to examine the state of the literature regarding the influence of stigma, both perceived social stigma and self-stigma, on the process of recovering from addiction with the assistance of treatment services.

\section{Methods}

\section{Search strategy}

PubMed, SCOPUS, and PsychINFO databases were searched on September 3, 2016, for all research articles that aimed to measure the impact of perceived social stigma and/or self-stigma on addiction treatment outcomes. The initial search terms were as follows: ("Social stigma" OR selfstigma) AND (Dependence, Addiction, OR Abuse). We then expanded our PubMed search by adding the MeSH terms "shame" and "substance-related disorders," producing the following search string: ("Shame"[Mesh] OR "social stigma" OR self-stigma OR stigma) AND "Substance-Related Disorders"[Mesh]. We also expanded our PsychINFO and SCOPUS searches to the following: ("social stigma" OR self-stigma) AND ("substance-related disorders" OR "drug abuse" OR “drug dependence" OR “alcohol abuse" OR "alcohol dependence" OR addiction OR "substance abuse"). The expanded search was repeated on November 3, 2017, to capture articles published after the initial search.

\section{Selection of literature}

After discarding duplicates, at least two people examined the title and abstract of each article for relevance. Articles that were clearly irrelevant were discarded immediately, whereas the full texts of the remaining papers were reviewed. Articles not published in English were discarded due to the 
lack of resources to translate. Also discarded were opinion pieces, conference abstracts, case reports or case series, commentaries, and review articles or book chapters without original research. The references of articles deemed relevant were scanned, and potential new articles were compiled and screened for relevance.

Articles deemed relevant were those that contained original qualitative or quantitative research with individuals who use psychoactive substances as subjects, whether or not the individuals were officially diagnosed with an SUD, and made an explicit link between stigma (perceived social or self) and outcomes of addiction treatment (ie, recovery).

Articles were excluded if they did not contain original research, the subjects did not include substance users (eg, service providers or family members only), they did not specifically address or measure stigma, the outcomes discussed were not related to addiction treatment (eg, physical health or social outcomes), or the type of addiction assessed was to nicotine, sex, or gambling. We did not exclude articles based on the legality of the substance nor on the basis of the quality of evidence.

Note that "perceived stigma" was based upon subjective reports, and we did not judge whether such stigma was objectively present. Also of note, the etiology of reports of stigma from health care professionals could be debated as a version of structural stigma (with employees representing the policies and attitudes of the places they work) or public stigma (with their attitudes representing their own core beliefs). We chose to interpret it as the latter, and instances of this are noted as perceived health care provider stigma, a subset of perceived social stigma, in the tables. All studies did not use the exact constructs of self-stigma and perceived self-stigma in their work. However, the constructs that we chose to include were those that were most closely related to self-stigma and perceived social stigma and measured some aspect of these terms

All the authors participated in the initial screening before the first two authors reviewed them again to ensure completeness. Disagreements, if any, were resolved through discussion and consensus. The PRISMA flowchart for selection of articles is shown in Figure 1.

\section{Data extraction}

For each article, we extracted reference information, location, sample size and participant demographics, substance studied, relevant constructs, measured outcomes, and relevant results. Note that the outcomes noted are treatment outcomes, not health or social outcomes due to substance misuse.
For qualitative articles, we extracted the analysis approach, whereas for quantitative articles we extracted construct measurement tools.

\section{Results}

Figure 1 shows the search and exclusion process, as per the PRISMA guidelines. The search initially yielded 5,952 articles, of which 840 were duplicates, and 187 more articles were added after searching references and citations. Examination of abstracts and titles led to the exclusion of 4,971 articles, leaving 328 full texts to be examined for relevance. Of all, 18 articles (eight qualitative, nine quantitative, and one mixed methods) met inclusion criteria and are summarized in Tables 1 and 2. Of these articles, four looked specifically at opiate addiction, five looked specifically at alcohol addiction, and the remaining nine looked at people with "substance abuse," SUDs, “drug use," or a combination of substances.

\section{Qualitative results}

Qualitative studies (summarized in Table 1) were united in finding that a significant portion of those seeking treatment for addiction experienced one or more types of stigma. Furthermore, both drug ${ }^{15}$ and alcohol ${ }^{16}$ users currently in treatment agreed that social and self-stigma made it more difficult to continue in a treatment program. In particular, Brooks ${ }^{17}$ found that stigmatizing aspects of treatment and negative emotions related to self-stigma interfered with participants' ability to connect with the treatment program and with the self. According to Brooks' analysis, connections with treatment are vital to successful recovery because they replace those previously provided by drug use. ${ }^{17}$ Similarly, in their study of drug users who had attempted treatment several times, Grønnestad and Sagvaag ${ }^{18}$ found that social exclusion and marginalization resulting from being labeled an "addict" interfered with participants' treatment attempts by instilling in them a desire to remain part of the drug scene, where they felt respected and included. ${ }^{18}$ Other drug users in methadone maintenance therapy (MMT) reported that social and self-stigma influenced their beliefs about their "ideal dose" of methadone and about how long it was acceptable to be in the program. ${ }^{19}$ Such beliefs were often in direct contradiction to best medical practices, thus endangering the ability of the user to successfully participate in the therapy program.

In addition to social and self-stigma regarding substance use, drug users also discussed stigmatizing aspects of therapy itself. Replacement therapy practices such as providing urine specimens under supervision, ${ }^{18}$ being segregated from 


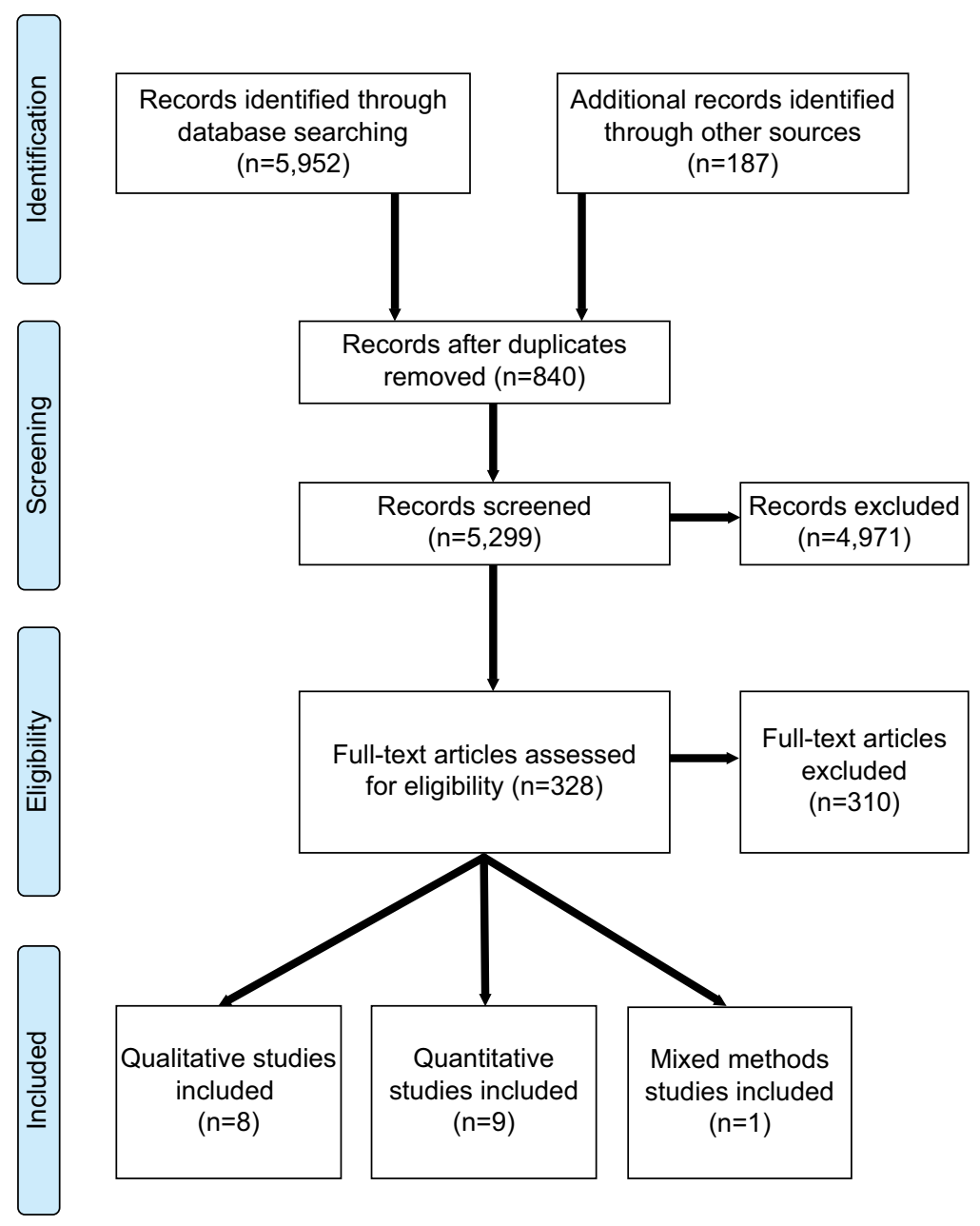

Figure I PRISMA flow diagram.

other patients in the pharmacy, and being supervised during substitute substance use ${ }^{20}$ were described as humiliating and stigmatizing. These experiences ultimately contributed to overall negative views of replacement therapy that in turn contributed to decisions to cease treatment for many participants. ${ }^{20}$ In contrast, other studies suggested that a notable lack of judgment and stigma from treatment program staff could help motivate those with SUDs to stay in treatment. For example, alcohol users in both treatment ${ }^{21}$ and harm reduction programs ${ }^{22}$ reported that the lack of stigma from treatment and program staff was a factor that encouraged compliance and continuation of services. At least one study suggested that such understanding behavior from treatment staff may have had an even stronger effect than the negative influences of social and self-stigma. All participants in Tang's ${ }^{23}$ study reported strong social and structural stigma associated with MMT. These participants also specifically noted the lack of stigma from MMT staff. Notably, no individual in this study who eventually dropped out of MMT cited stigma as a reason that they had ceased treatment.

\section{Quantitative results}

Mak et $\mathrm{al}^{24}$ provided the strongest statistical evidence for an effect of stigma on recovery. Using structural equation modeling, they showed that perceived social stigma and health care provider stigma led to increased self-stigma and decreased engagement with treatment. These factors in turn led to worsened recovery, both personal and clinical. ${ }^{24}$ In contrast to these cross-sectional findings, however, are those of Link et al, who found that SUD symptoms improved over time, regardless of stigma. ${ }^{25}$

Other quantitative studies (summarized in Table 2) suggested that several personal variables may impact recovery indirectly, perhaps through their influence on self-stigma. Specifically, two cross-sectional studies found no relationship between stigma and prior treatment attempts, ${ }^{26,27}$ whereas a 


\begin{tabular}{|c|c|c|c|c|}
\hline 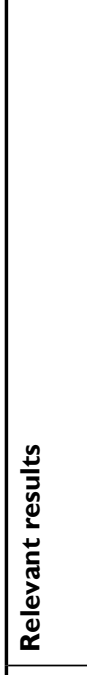 & 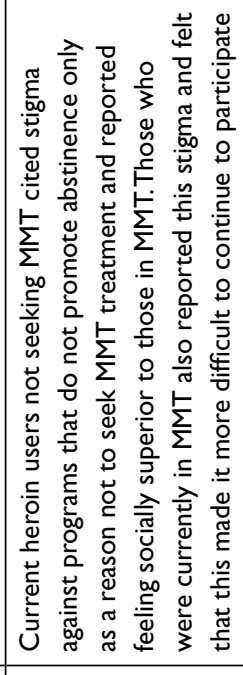 & 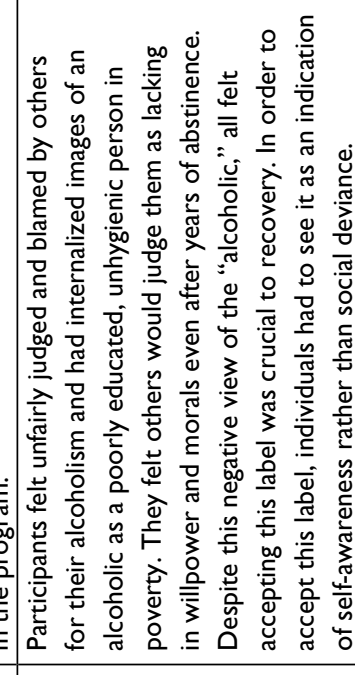 & 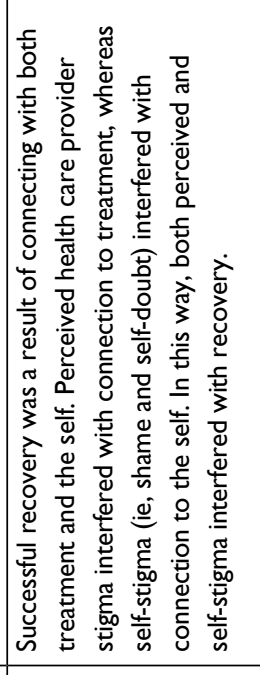 & 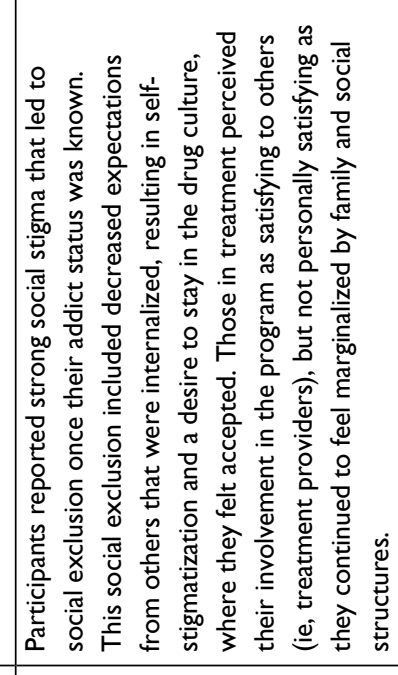 \\
\hline & 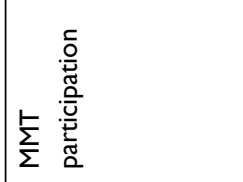 & 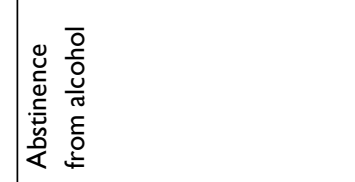 & 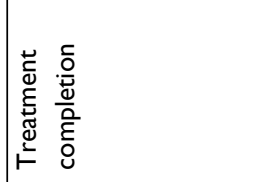 & 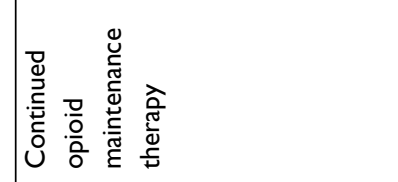 \\
\hline 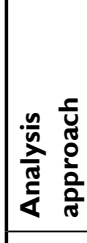 & 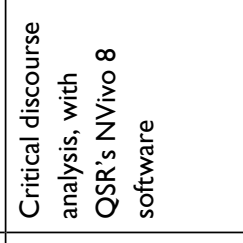 & 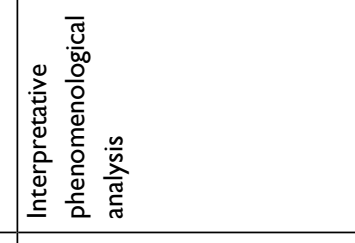 & 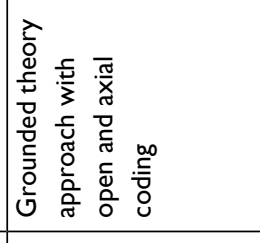 & 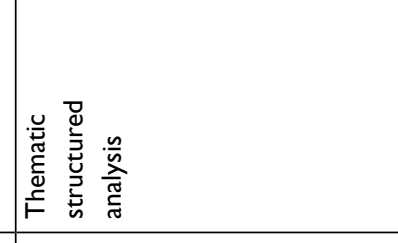 \\
\hline 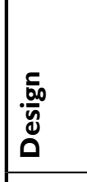 & 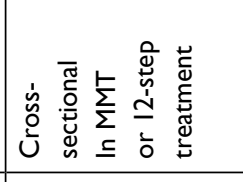 & 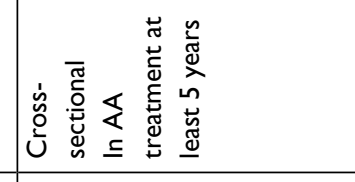 & 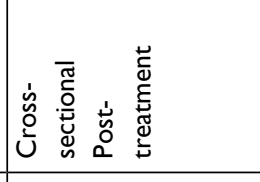 & 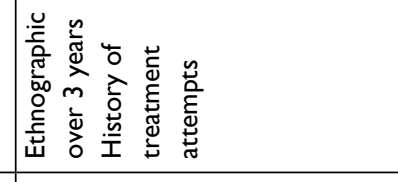 \\
\hline 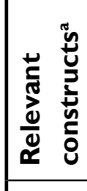 & 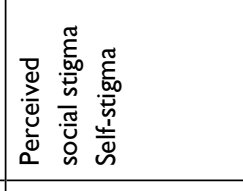 & 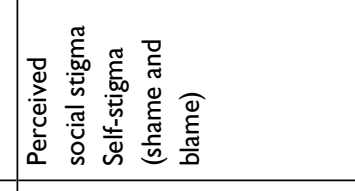 & 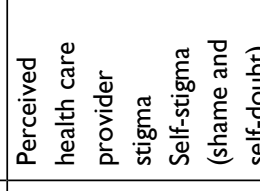 & 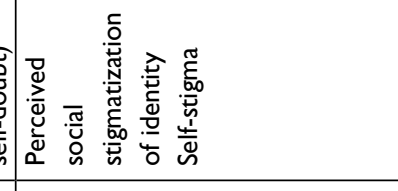 \\
\hline & 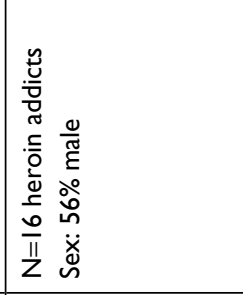 & 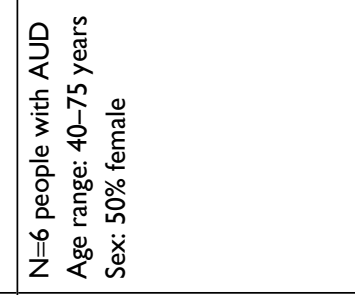 & 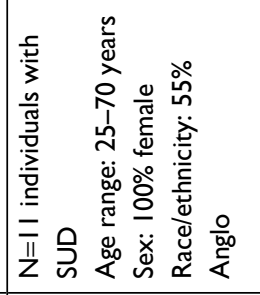 & 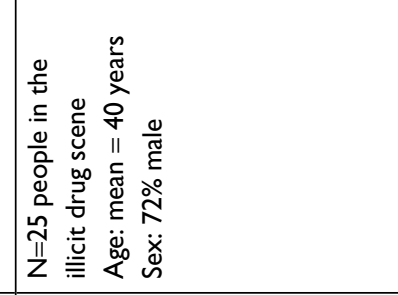 \\
\hline 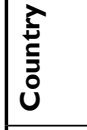 & 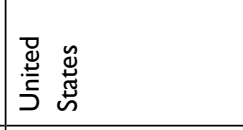 & 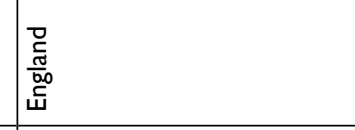 & 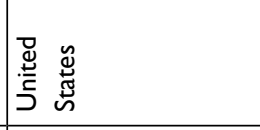 & $\begin{array}{l}\text { 弯 } \\
\text { 吾 } \\
\end{array}$ \\
\hline 害 & 总 & 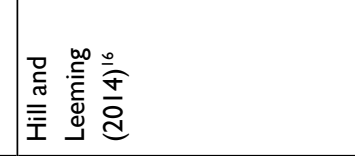 & 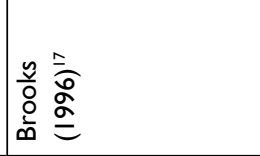 & 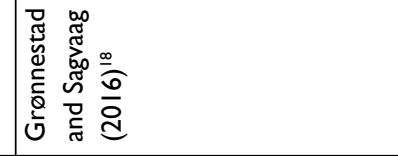 \\
\hline
\end{tabular}




\begin{tabular}{|c|c|c|c|c|c|}
\hline 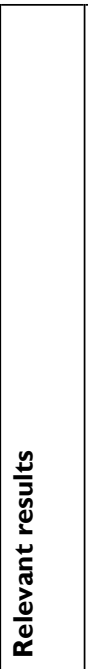 & 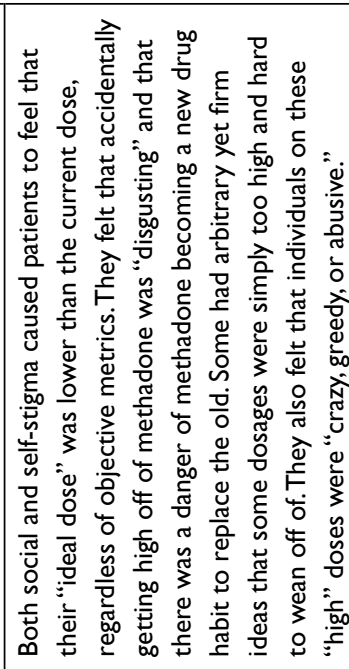 & 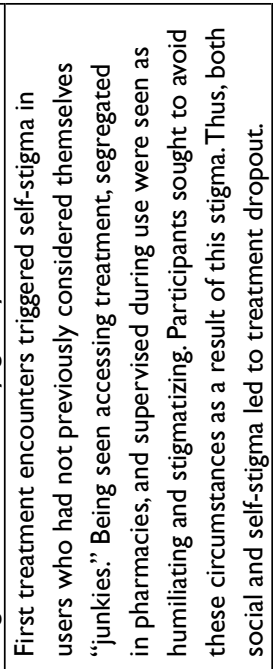 & 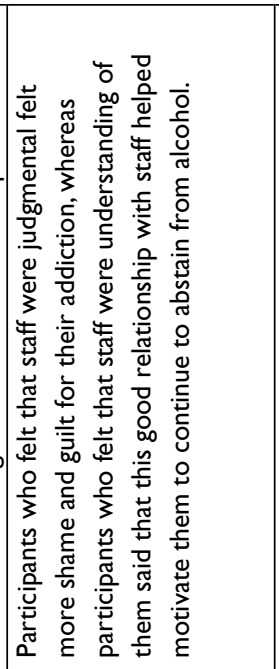 & 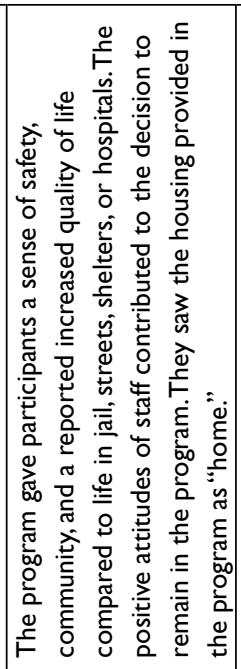 & 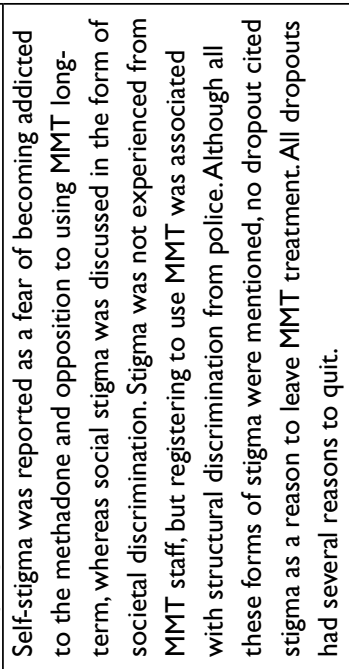 \\
\hline 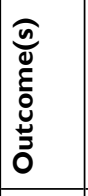 & 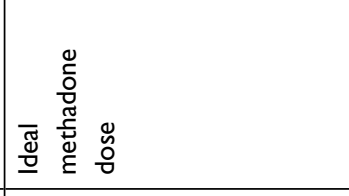 & 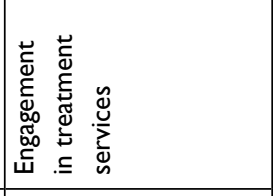 & 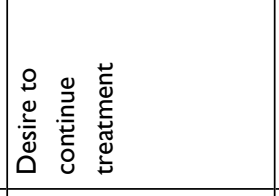 & 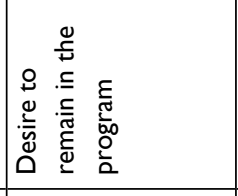 & 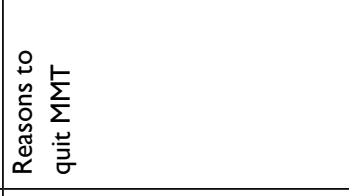 \\
\hline 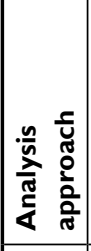 & 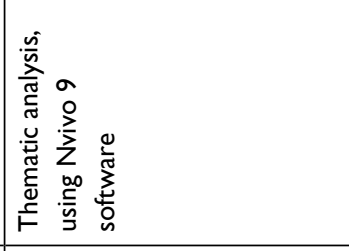 & 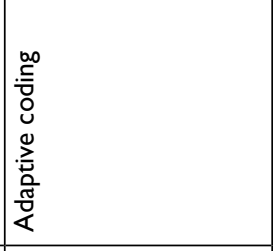 & 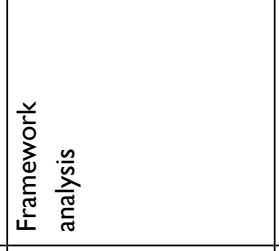 & 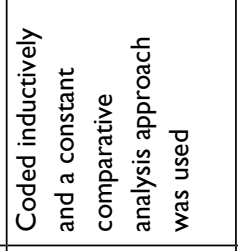 & 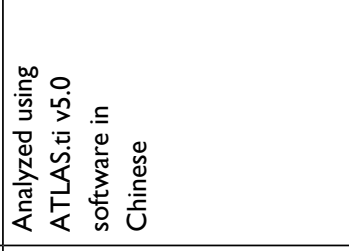 \\
\hline 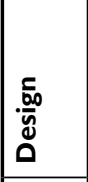 & 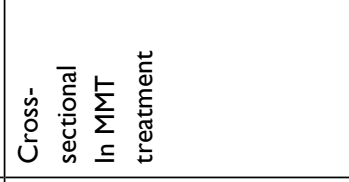 & 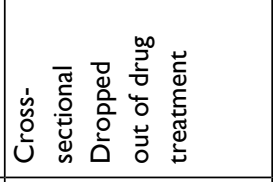 & 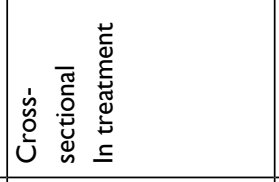 & 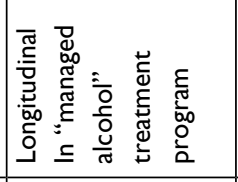 & 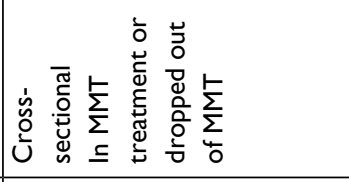 \\
\hline 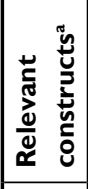 & 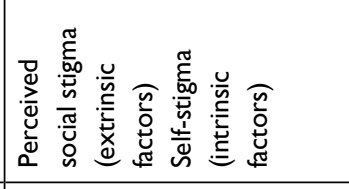 & 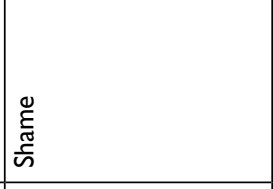 & 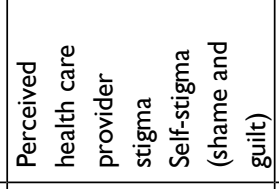 & 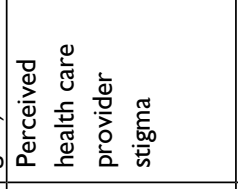 & 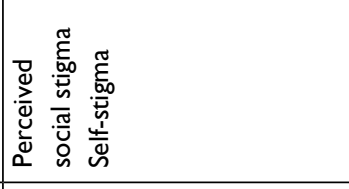 \\
\hline 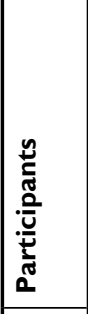 & 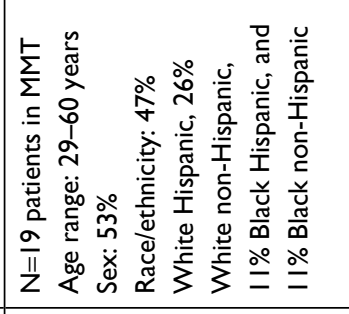 & 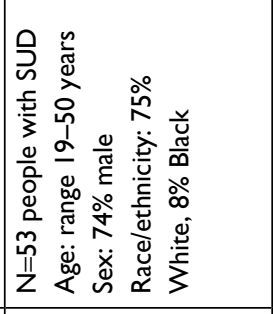 & 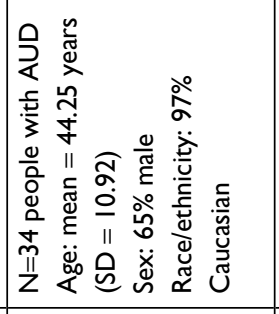 & 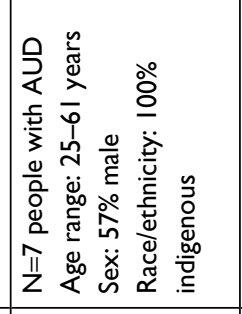 & 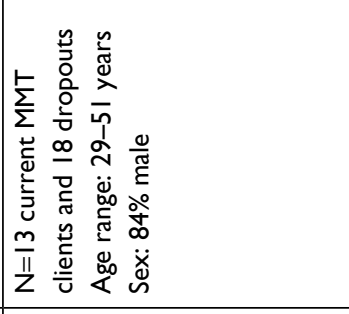 \\
\hline 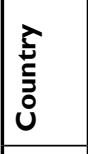 & 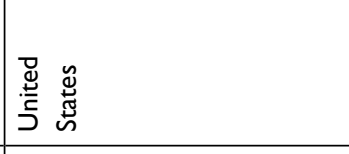 & 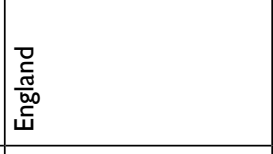 & 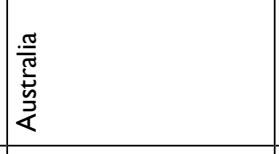 & 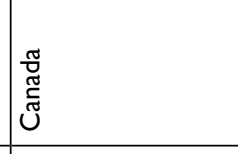 & 胥 \\
\hline $\begin{array}{l}\overrightarrow{\hat{\theta}} \\
\overline{\ddot{n}}\end{array}$ & 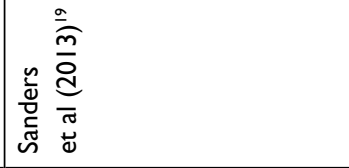 & 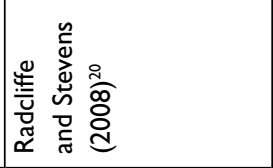 & 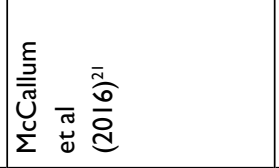 & 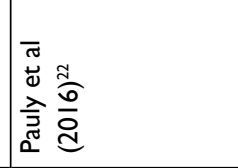 & 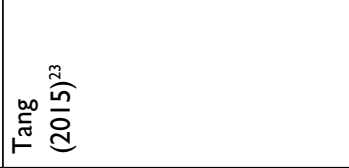 \\
\hline
\end{tabular}




\begin{tabular}{|c|c|c|c|c|}
\hline 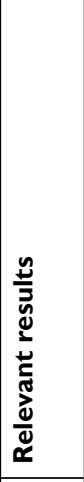 & 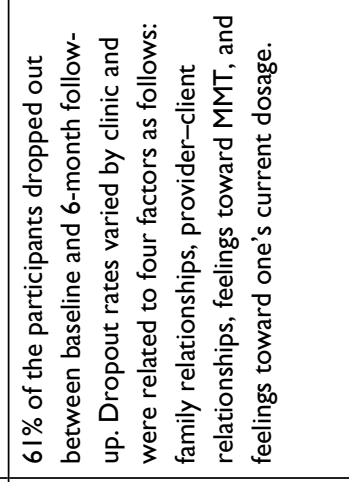 & 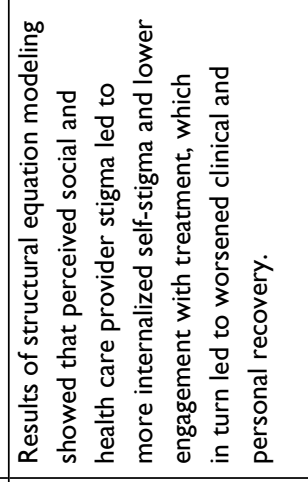 & 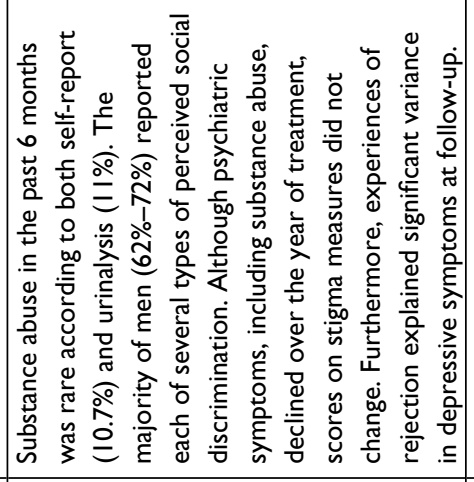 & 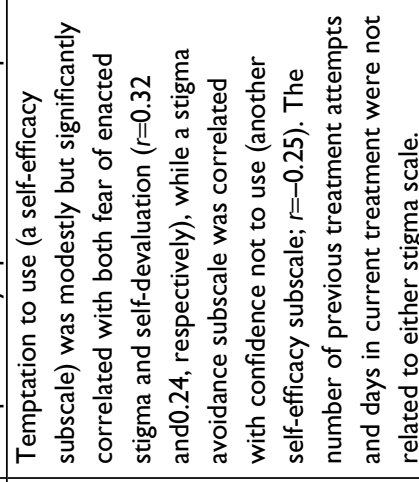 \\
\hline 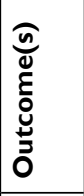 & 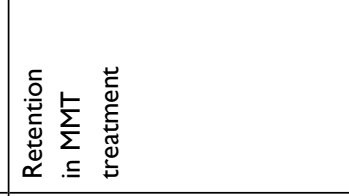 & 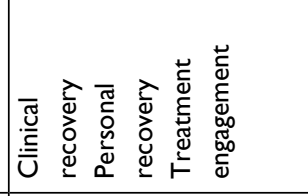 & 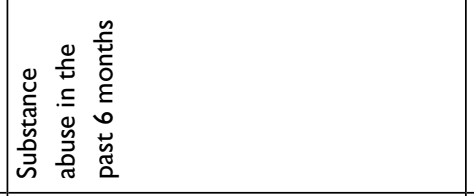 & 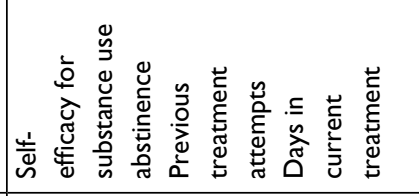 \\
\hline 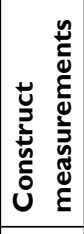 & 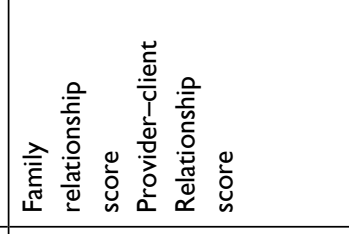 & 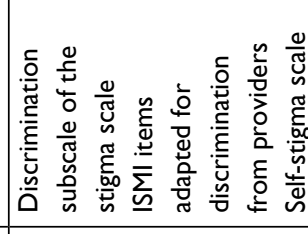 & 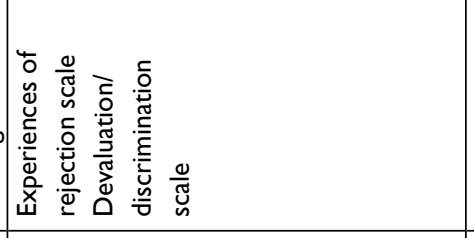 & 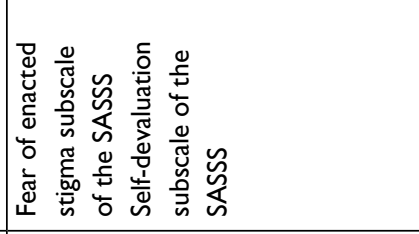 \\
\hline 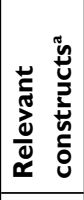 & 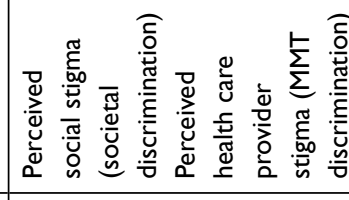 & 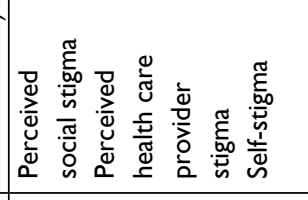 & 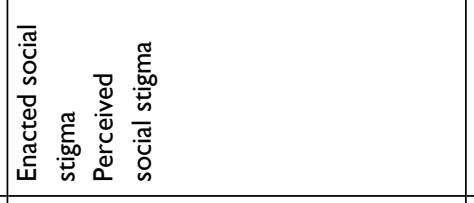 & 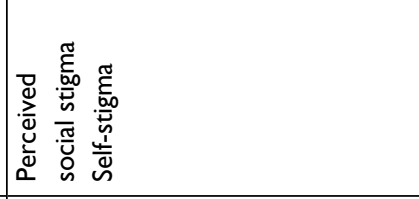 \\
\hline 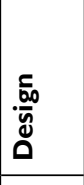 & 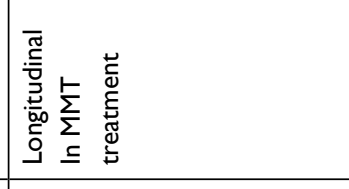 & 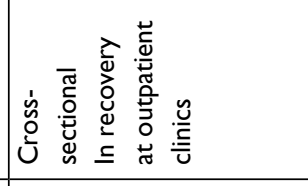 & 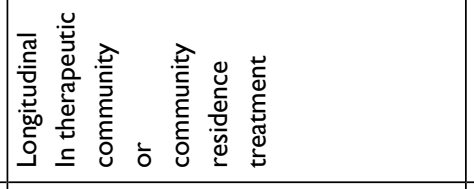 & 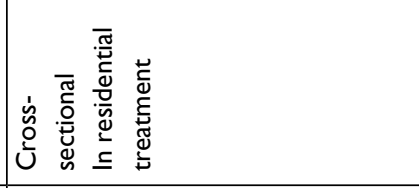 \\
\hline 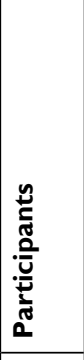 & 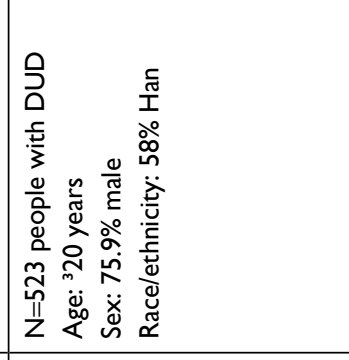 & 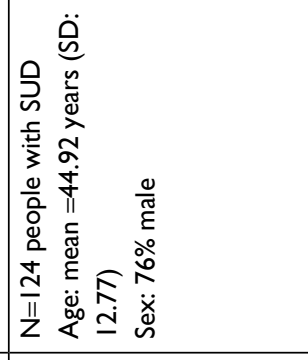 & 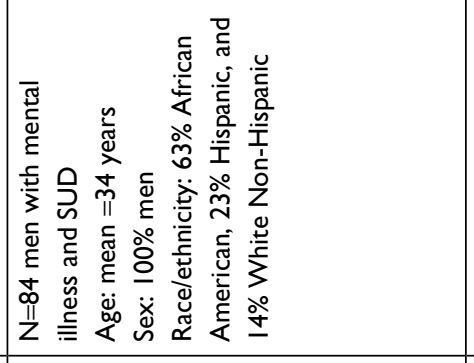 & 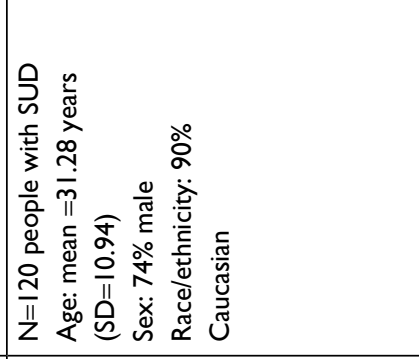 \\
\hline نे & 苞 & 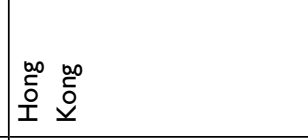 & 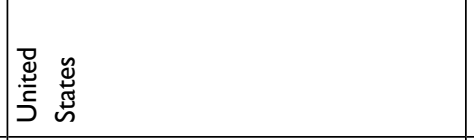 & 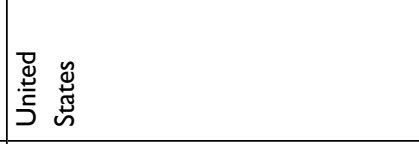 \\
\hline 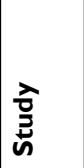 & 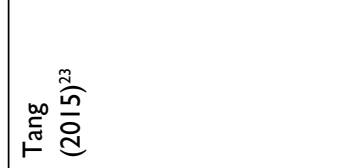 & 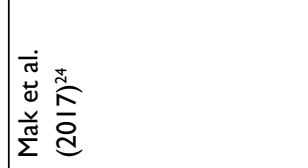 & 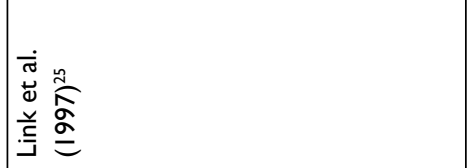 & 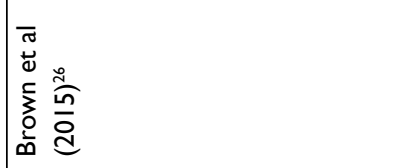 \\
\hline
\end{tabular}




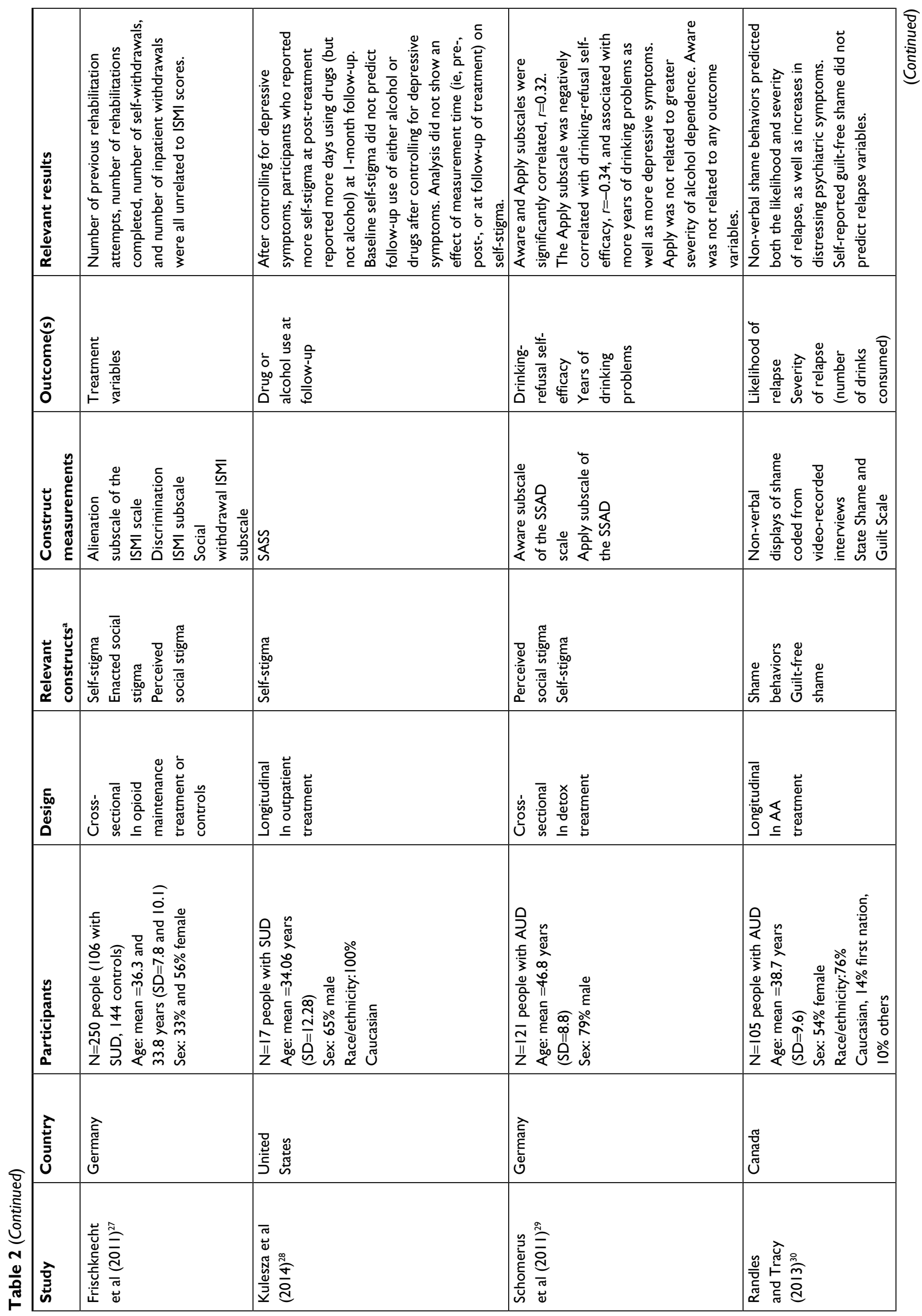




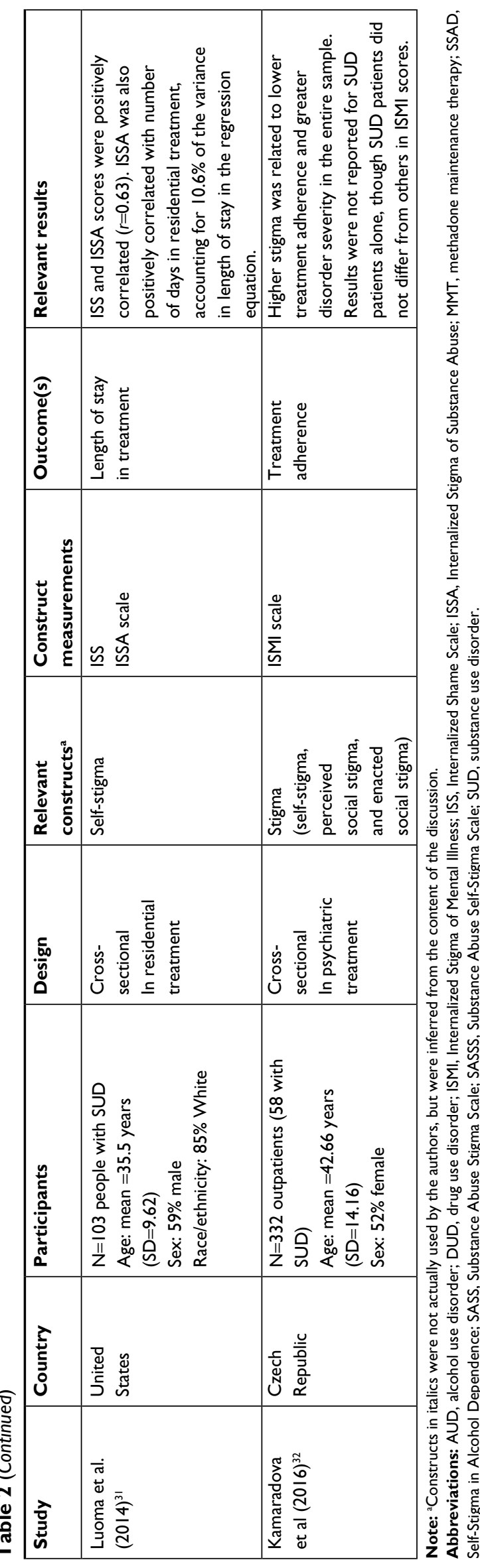

longitudinal study showed that baseline self-stigma did not predict substance use at follow-up. ${ }^{28}$ However, one of these studies found that self-stigma was related to being tempted to use and a lack of confidence not to use, ${ }^{26}$ and a fourth study found that self-stigma was related to lower drinking-refusal self-efficacy. ${ }^{29}$ Furthermore, Tang ${ }^{23}$ found that MMT dropouts cited family relationships, provider-client relationships, feelings toward MMT, and feelings toward current dosage as reasons to leave treatment - while the qualitative data in Table 1 suggest that all four of these factors are influenced by stigma, no dropout in the study directly cited stigma as a reason to leave treatment. ${ }^{23}$

Results from Randles and Tracy ${ }^{30}$ also highlight the potential indirect effects of negative emotions related to self-stigma. They found that non-verbal shame displays, but not self-reported guilt-free shame, predicted relapse in individuals participating in Alcoholics Anonymous. ${ }^{30}$ In seeming contrast, Luoma et $\mathrm{al}^{31}$ found that the more selfstigma in an individual with SUD, the longer their stay in a residential treatment program. Although this might seem to indicate higher adherence to treatment, the authors attribute it to a desire to retreat into the residential treatment setting rather than to return to outside life with high levels of selfstigma and decreased self-efficacy. Another study offers an additional explanation for this finding. Kamaradova et $\mathrm{al}^{32}$ found that higher stigma was related to greater disorder severity and lower treatment adherence. Note, however, that both studies were cross-sectional, thus it is not possible to determine the directionality of these relationships.

\section{Discussion}

The goal of this review was to determine the effect of perceived social and self-stigma on the process of recovering from addiction with the assistance of treatment services in order to help inform future research, clinical practice, and health policy. The studies compiled here were united in demonstrating that individuals with SUDs face a large amount of stigma from various sources, including themselves. Furthermore, these studies offer evidence that these different stigmas have an impact on variables that may, in turn, affect the likelihood that a person will complete treatment or achieve recovery. These variables include desire to continue in treatment, ${ }^{15,18,21,22,24}$ engagement with treatment ${ }^{17,20,24}$ (including opinion as to ideal methadone dose), ${ }^{19}$ and selfefficacy. ${ }^{26,33}$ However, the direct influence of various types of experienced stigma on a person's ultimate recovery with the assistance of treatment services remains unclear. The strongest evidence for such a direct relationship comes from 
Mak et al, ${ }^{24}$ who used validated measures of both clinical and personal recovery in addition to validated measures of stigma. These cross-sectional results are, however, contradicted by three longitudinal studies, which found that pre-treatment stigma did not predict post-treatment substance use after depression symptoms were controlled for, ${ }^{28}$ stigma ratings did not change even as substance use symptoms improved, ${ }^{25}$ and MMT dropouts did not cite stigma as a reason they had to quit treatment. ${ }^{23}$ Only one longitudinal study agrees with Mak et al's findings, ${ }^{24}$ but its measure of stigma (nonverbal shame behaviors) is unusual in the research literature. ${ }^{30}$

Other cross-sectional quantitative results contradict Mak et al's findings, ${ }^{26,27}$ whereas still others provide little evidence of causality. Kamaradova et al, ${ }^{32}$ for example, showed a correlation between stigma and treatment adherence, but adherence was also correlated with disorder severity. Schomerus et $\mathrm{al}^{29}$ too showed a correlation between a stigma subscale and years of problem drinking. However, this same subscale was also correlated with depressive symptoms. Thus, it is not possible to use these studies as evidence of an influence of stigma on adherence. The study by Luoma et $\mathrm{al}^{31}$ is the study that does appear to support a relationship between stigma and treatment adherence, but the authors themselves argue that staying longer in residential treatment was more likely about staying hidden away rather than engaging with treatment. Finally, one qualitative study suggests that stigma can have a positive influence on recovery when the individual transforms stigmatizing labels such as "alcoholic" from markers of social deviance to indications of self-awareness. ${ }^{16}$

\section{Limitations}

As with any review, our conclusions are only as good as the studies upon which they are based. Although we feel confident that our methods have provided a comprehensive look at the published literature addressing our question, only very few articles in the field of addiction were suitable for inclusion. That is, we found few studies that attempted to directly assess the impact of stigma on recovery achieved with the use of addiction treatment services. One explanation for the low volume of literature in this area may be the concept of recovery itself. Given that recovery is a sustained process ${ }^{14}$ rather than a specific end point, it is understandably difficult to operationalize variables to capture it. ${ }^{34}$ In the studies summarized here, recovery was assessed in various ways, from the fragile "desire to continue in treatment" 21 to more robust validated measures of personal and clinical recovery. ${ }^{24}$ Furthermore, not everyone agrees on what recovery is - in programs like MMT, recovery includes continued use of the substitute medication, whereas programs such as AA view recovery as complete abstinence from use. It is possible that seeming contradictions in the literature are attributable to such differences in measurement and definition of the construct of recovery rather to any deeper disagreements about the relationship between stigma and recovery.

In a similar vein, it should also be noted that there is diversity in the measurement and terminology used to look at the construct of stigma itself. The qualitative studies reviewed in this study, while attempting to utilize sound methodologies, are inherently subjective both in terms of reports from participants and in terms of interpretations by researchers. It is possible that a researcher free of prior beliefs about stigma's role in recovery would come to similar conclusions (ie, extract the theme of "stigma" from the data and/or elicit data that contain such themes from participants), but it is difficult to imagine that the researchers in these studies were so free from prior knowledge. Additionally, every quantitative study in Table 2 used a different measure for stigma, many with subscales measuring constructs such as devaluation, discrimination, state shame, guilt, etc. Each of these constructs, in turn, relate to one or more of several types of stigma (ie, self-stigma, health care provider stigma, and perceived social stigma). Given such diversity in measurement, it is little surprise that the results of these studies do not necessarily cohere elegantly.

A third limitation of this review is the imbalance in the number of articles pertaining to alcohol recovery (three in Table 1 and two in Table 2) compared to those pertaining to drug recovery (six in Table 1 and eight in Table 2). Studies of MMT therapy suggest that it is a particularly stigmatizing type of treatment, ${ }^{15,19,20,23}$ and, thus, it may present challenges for those undertaking it that are unlike those faced by individuals in alcohol treatment programs. It is worth considering that stigma may have different impacts on recovery depending upon both the substance one is using and the type of treatment one is seeking.

Finally, sampling bias is an important factor in all research, ${ }^{35}$ but perhaps especially so with populations of substance users. Seven (39\%) of the studies reviewed were conducted in the United States, whereas two (11\%) were conducted in each of three countries (Canada, England, and Germany), and the remaining five (28\%) were conducted in other nations worldwide. Nations can vary significantly in how they view and deal with SUDs, both on a social/cultural level and on an institutional level. Countries such as Russia, Ukraine, and China have both strong social prohibitions against substance misuse and mandatory registration systems 
for substance misusers seeking help that may significantly alter the relationship between stigma and recovery, not the least by influencing a person's decision to seek help in the first place. ${ }^{23,36,37}$ Thus, a wider array of studies from more countries would help clarify any nation-specific effects. Even within nations, larger sample populations from various treatment service providers and including subpopulations, such as those based on gender, race, or sexual orientation, would help clarify the relationship and support generalizability of the findings.

\section{Future research}

To get answers related to the effect of perceived social and self-stigma on recovery in people with addiction who are seeking treatment, both recovery and stigma must be well defined and measured by multiple researchers with the same validated tools. Work on mental health stigma is much further along than research on the same attitudes and outcomes in addiction. Although many of the same principles appear to be relevant and applicable, the social stigma is worse toward addiction because it is more often viewed as under the individual's control or as a moral failing, rather than as a disease. ${ }^{29}$ Future research could also attempt to study the populations that were not covered in this review as discussed earlier.

\section{Summary}

This review of studies of recovery outcomes in individuals seeking treatment for SUDs suggests a negative, though perhaps indirect, role for self-stigma and perceived social stigma. The question then arises as to how to improve the situation. The qualitative studies demonstrated the complexity of emotions and processing that needs to occur for people who are attempting to recover from addiction. For that reason, in spite of the much-needed advances in pharmacotherapy interventions for addiction that are occurring, continued attention to the psychological needs of the recovering person is important as well. An interesting finding in this review was the impact of the stigmatizing attitudes of health care professionals. van Boekel et $\mathrm{al}^{11}$ showed that health care professionals who were addiction specialists had higher regard for people with SUDs than professionals in general psychiatry or general practice, a replication of previous reports, ${ }^{38}$ but this review suggested that even such professionals may be engaging in treatment protocols that enhance stigma, however, inadvertently. Treatment systems (to include primary care and mental health) could consider how to reduce the perception of stigma toward clients from staff and make them aware of the impact their attitudes and treatment practices have. More welcoming services, concern for language choices, and more training on the effect of biases are other options to be considered. The perception of negative judgment at the interface of patients and health care systems has a deleterious effect on willingness to seek treatment as well as the outcomes of treatment. ${ }^{39}$

Larger than health care systems, societal decisions have a role in perpetuating perceptions of stigma and reported discrimination that ultimately impact treatment decisions and outcomes. ${ }^{40}$ Decisions to criminalize substance use, punish pregnant women who are addicted, limit insurance coverage for addiction services, offer poor reimbursement for addiction services to providers, and the lack of availability of universally affordable treatment can all contribute to the perception (and oftentimes reality) of social stigma that many people feel and internalize.

\section{Conclusion}

This review identified 18 articles that added evidence to the discussion of the role of self-stigma and perceived social stigma on recovery and treatment outcomes. While there were significant findings, much more work needs to be done.

\section{Acknowledgments}

The authors would like to thank Richard Vath, MA for his invaluable help in the conceptualization and early organization of the paper. The inclusion of the construct of "shame" in our search was supported by PubMed MeSH indexing, which shows that "social stigma" was indexed as "shame" from 1975 until 2010.

\section{Disclosure}

The authors report no conflicts of interest in this work.

\section{References}

1. Association AP. Diagnostic and Statistical Manual of Mental Disorders. 5th ed. Arlington, VA: American Psychiatric Association; 2013.

2. Goffman E. Stigma: Notes on the Management of Spoiled Identity. Englewood Cliffs, NJ: Prentice Hall; 1963.

3. Room R, Rehm J, Paglia A, Ustun TB. Cross cultural views on stigma, valuation, parity, and societal views towards disability. In: Ustun TB, editor Disability and Culture. Seattle: Hogrefe \& Huber Publishers; 2001:247-291.

4. Palomar J, Halkitis PN, Kiang M. Perceived public stigma and stigmatization in explaining lifetime illicit drug use among emerging adults. Addict Res Theory. 2012;21(6).

5. Spears R, Manstead ASR. The social context of stereotyping and differentiation. Eur J Soc Psychol. 1989;19(2):101-121.

6. Room R, Reuter P. How well do international drug conventions protect public health? Lancet. 2012;379(9810):84-91.

7. Schomerus G, Lucht M, Holzinger A, Matschinger H, Carta MG, Angermeyer MC. The stigma of alcohol dependence compared with other mental disorders: a review of population studies. Alcohol Alcohol. 2011;46(2):105-112. 
8. Luoma JB, Twohig MP, Waltz T, et al. An investigation of stigma in individuals receiving treatment for substance abuse. Addict Behav. 2007;32(7):1331-1346.

9. Luoma JB, O'Hair AK, Kohlenberg BS, Hayes SC, Fletcher L. The development and psychometric properties of a new measure of perceived stigma toward substance users. Subst Use Misuse. 2010;45(1-2):47-57.

10. Livingston JD, Milne T, Fang ML, Amari E. The effectiveness of interventions for reducing stigma related to substance use disorders: a systematic review. Addiction. 2012;107(1):39-50.

11. van Boekel LC, Brouwers EP, van Weeghel J, Garretsen HF. Stigma among health professionals towards patients with substance use disorders and its consequences for healthcare delivery: systematic review. Drug Alcohol Depend. 2013;131(1-2):23-35.

12. Cumming C, Troeung L, Young JT, Kelty E, Preen DB. Barriers to accessing methamphetamine treatment: A systematic review and metaanalysis. Drug Alcohol Depend. 2016;168:263-273.

13. Moos RH. Iatrogenic effects of psychosocial interventions for substance use disorders: prevalence, predictors, prevention. Addiction. 2005;100(5):595-604.

14. White WL. Addiction recovery: its definition and conceptual boundaries. J Subst Abuse Treat. 2007;33(3):229-241.

15. Frank D. The trouble with morality: the effects of 12-step discourse on addicts' decision-making. J Psychoactive Drugs. 2011;43(3):245-256.

16. Hill JV, Leeming D. Reconstructing 'the Alcoholic': Recovering from Alcohol addiction and the stigma this entails. Int J Ment Health Addict. 2014;12(6):759-771.

17. Brooks AJ. Factors Influencing Women's Recovery from Substance Abuse: A Grounded Theory Approach. [Dissertation], University of Arizona; 1996.

18. Grønnestad TE, Sagvaag H. Stuck in limbo: illicit drug users' experiences with opioid maintenance treatment and the relation to recovery. Int J Qual Stud Health Well-being. 2016;11:31992.

19. Sanders JJ, Roose RJ, Lubrano MC, Lucan SC, Meaning LSC. Meaning and methadone: patient perceptions of methadone dose and a model to promote adherence to maintenance treatment. J Addict Med. 2013;7(5):307-313.

20. Radcliffe P, Stevens A. Are drug treatment services only for 'thieving junkie scumbags'? Drug users and the management of stigmatised identities. Soc Sci Med. 2008;67(7):1065-1073.

21. McCallum SL, Mikocka-Walus AA, Gaughwin MD, Andrews JM, Turnbull DA. 'I'm a sick person, not a bad person': patient experiences of treatments for alcohol use disorders. Health Expect. 2016;19(4):828-841.

22. Pauly BB, Gray E, Perkin K, et al. Finding safety: a pilot study of managed alcohol program participants' perceptions of housing and quality of life. Harm Reduct J. 2016;13(1):15.

23. Tang S. Factors Associated with Effectiveness of Methadone Maintenance Treatment in Yunnan Province of China. Los Angeles: UCLA; 2015.

24. Mak WW, Chan RC, Wong SY, et al. A Cross-Diagnostic Investigation of the Differential Impact of Discrimination on Clinical and Personal Recovery. Psychiatr Serv. 2017;68(2):159-166.
25. Link BG, Struening EL, Rahav M, Phelan JC, Nuttbrock L. On stigma and its consequences: evidence from a longitudinal study of men with dual diagnoses of mental illness and substance abuse. J Health Soc Behav. 1997;38(2):177-190.

26. Brown SA, Kramer K, Lewno B, Dumas L, Sacchetti G, Powell E. Correlates of self-stigma among individuals with substance use problems. Int J Ment Health Addict. 2015;13(6):687-698.

27. Frischknecht U, Beckmann B, Heinrich M, et al. The vicious circle of perceived stigmatization, depressiveness, anxiety, and low quality of life in substituted heroin addicts. Eur Addict Res. 2011;17(5):241-249.

28. Kulesza M, Ramsey S, Brown R, Larimer M. Stigma among individuals with substance use disorders: does it predict substance use, and does it diminish with treatment? J Addict Behav Ther Rehabil. 2014;3(1):1000115.

29. Schomerus G, Corrigan PW, Klauer T, Kuwert P, Freyberger HJ, Lucht M. Self-stigma in alcohol dependence: consequences for drinkingrefusal self-efficacy. Drug Alcohol Depend. 2011;114(1):12-17.

30. Randles D, Tracy JL. Nonverbal displays of shame predict relapse and declining health in recovering alcoholics. Clinical Psychological Science. 2013;1(2):149-155.

31. Luoma JB, Kulesza M, Hayes SC, Kohlenberg B, Larimer M. Stigma predicts residential treatment length for substance use disorder. Am J Drug Alcohol Abuse. 2014;40(3):206-212.

32. Kamaradova D, Latalova K, Prasko J, et al. Connection between selfstigma, adherence to treatment, and discontinuation of medication. Patient Prefer Adherence. 2016;10:1289-1298.

33. Schomerus G, Corrigan PW, Klauer T, Kuwert P, Freyberger HJ, Lucht M. Self-stigma in alcohol dependence: consequences for drinkingrefusal self-efficacy. Drug Alcohol Depend. 2011;114(1):12-17.

34. Kaskutas LA, Borkman TJ, Laudet A, et al. Elements that define recovery: the experiential perspective. J Stud Alcohol Drugs. 2014;75(6):999-1010.

35. Tsogia D, Copello A, Orford J. Entering treatment for substance misuse: a review of the literature. J Ment Health. 2001;10(5):481-499.

36. Bobrova N, Rhodes T, Power R, et al. Barriers to accessing drug treatment in Russia: a qualitative study among injecting drug users in two cities. Drug Alcohol Depend. 2006;82(Suppl 1):S57-S63.

37. Bojko MJ, Mazhnaya A, Makarenko I, et al. "Bureaucracy \& beliefs": assessing the barriers to accessing opioid substitution therapy by people who inject drugs in Ukraine. Drugs. 2015;22(3):255-262.

38. Gilchrist G, Moskalewicz J, Slezakova S, et al. Staff regard towards working with substance users: a European multi-centre study. Addiction. 2011;106(6):1114-1125.

39. van Boekel LC, Brouwers EP, van Weeghel J, Garretsen HF. Stigma among health professionals towards patients with substance use disorders and its consequences for healthcare delivery: systematic review. Drug Alcohol Depend. 2013;131(1-2):23-35.

40. Corrigan P, Schomerus G, Smelson D. Are some of the stigmas of addictions culturally sanctioned? Br J Psychiatry. 2017;210(3):180-181.
Substance Abuse and Rehabilitation

\section{Publish your work in this journal}

Substance Abuse and Rehabilitation is an international, peer-reviewed, open access journal publishing original research, case reports, editorials, reviews and commentaries on all areas of addiction and substance abuse and options for treatment and rehabilitation. The manuscript management system is completely online and includes a very quick and fair

\section{Dovepress}

peer-review system. Visit http://www.dovepress.com/testimonials.php to read real quotes from published authors. 